\title{
THE USE OF RESEARCH PORTFOLIOS IN SCIENCE POLICY
}

NICHOLAS S. VONORTAS AND ISMAEL RÀFOLS

DOI: $10.22163 /$ fteval.2019.338

Acknowledgement: This research has been supported by the Science of Science and Innovation Policy program of the US National Science Foundation with the award SMA1734829 (2017) "Science Policy Research Report: The Use of Research Portfolios in Science Policy" to the George Washington University.

\section{ABSTRACT}

A ny research funding and/or research-performing organization in the public, private, and non-profit sectors needs to adopt a portfolio-wide perspective to R\&D management to better align research project investments with the organization's overall strategic goals. Private sector firms have increasingly done so utilizing powerful new methodological tools and large amounts of data becoming available. In contrast, with relatively few exceptions, public R\&D management still tends to base selection processes on the excellence of individual projects according to peers rather than considering the merits of the whole portfolio. There are good reasons for additional caution which, besides the usual inertia and the resistance by scientists trusting the peer review process, include multiple objectives of public programs, long-term accrual of results and associated uncertainties, and difficulty to monetize or value. This report argues it is high time for public R\&D management to move forward. Portfolio analysis should not be applied similarly across the board. It will serve different purposes for different types of public R\&D programs depending on risk/uncertainty, data availability, and target clarity (ability to define unambiguous program goals). Not all methodologies will be appropriate to all programs. Nonetheless, the toolkit, data depositories, and computing capability have expanded tremendously during the past couple of decades to render such experimentation possible and absolutely necessary.

\section{INTRODUCTION}

Public research and development (RGD) is widely believed to be important for improving knowledge, fostering economic growth and social well-being. Consequently, research and innovation policy can be seen as an investment and be designed, in part, in terms of expected socioeconomic 'returns', their timing and degrees of risk taking (Borrás and Edquist, 2014). Analysts have, however, struggled to provide robust, widely acceptable methods to support decision-making for future investments. This has led to arguments of insufficient empirical or theoretical basis for making or justifying specific choices for investment (ITG, 2008, p. 1) and perceptions that public research is not adequately addressing societal needs such as global health (Sarewitz and Pielke, 2007). While there has been significant methodological progress during the past ten years or so - some of which is surveyed in this report - the issue is far from resolved.

A research portfolio is defined as the set of research activities supported by a funding and/or research-performing organization or a group of agencies/organizations. In large technology-intensive companies, portfolio-wide perspective to R\&D management has long been applied as a means of better aligning research project investments with the firm's overall strategic goal of economic return maximization (Schilling, 2017). Still, with relatively few exceptions in the public sector (Ruegg, 2007), public R\&D management still tends to base selection processes on the individual excellence of projects according to peers rather than considering the merits of the whole portfolio (Linton and Vonortas, 2015; Linquiti, 2015). Nascent attempts such as the Office of Portfolio Analysis at the National Institutes of Health are commentable but have yet to reach full acceptance, often due to resistance by the client community (scientists). In some contexts, research portfolios are described as 'profiles' (e.g. in German universities, Meier and Schimank, 2010).

There is no question that the appraisal of research portfolios is challenging across the board. It may be relatively more so in the public sector. Besides the usual inertia and the resistance by scientists trusting the peer review process, there are other serious reasons why this may be so: multiple objectives, project interdependency, difficulty to monetize or value. Public programs will frequently have multiple objectives requiring multiple (perhaps incompatible) performance measures for evaluation. Research projects and programs in public research portfolios can be interdependent. Their outputs are typically removed from the market, thus making monetary valuations arbitrary. Hence, accounting for public research investment in purely monetary terms is not advisable when looking at investments with uncertain evolution and payoff structure, as well as "fuzziness" in terms of the social desirability of the "impact" and associated values.

Improvements in data processing and visualization techniques (Börner et al., 2003; Van Eck and Waltman, 2014), coupled with conceptual developments in research and analytical methods better handling risk (Lo Nigro et al., 2016; Luehrman, 1998; Vonortas and Desai, 2007) in the last couple of decades, however, suggest that research portfolio approaches offer the possibility of improving the performance of R\&D programs by identifying gaps and opportunities. They also help in making more transparent the multiple goals of most public R\&D programs - thus facilitating the alignment of research with its various welfare, environmental, security and economic missions (Wallace and Rafols, 2015).

The rest of this paper runs as follows. Section 2 recounts the analytical literature concentrating on the modeling aspect of research portfolio 
analysis to quantify the returns to uncertain R\&D. Section 3 recounts the literature using the notion of research portfolio as a heuristic for deliberation on research priorities and project selection in the face of incomplete quantifiable information, deep uncertainty, and lack of agreement on goals. Section 4 introduces recent advances in data availability, processing and visualization techniques which greatly facilitate portfolio management. We draw overall conclusions for policy decision makers in Section 5.

\section{R\&D PORTFOLIO MODELLING}

\subsection{ECONOMIC APPROACHES}

Economic impact analysis is one part of an R\&D program evaluation. Quantitative economic appraisals of public sector-funded R\&D usually lean on capital budgeting methods extensively used in the private sector (Link and Scott, 2013). This analytical and theoretical framework has long been germane to the economics and business technology management literature. One critical aspect of this literature is the need to consider the counterfactual situation that would have existed should the RGD program in question had never materialized: the evaluation accounts for the incremental benefits between the two (additionality). A second critical aspect is the recognition of various types of spillovers, that is, circumstances where the (private) producer of knowledge cannot extract through the market system the full value the new knowledge adds to the economy. Such spillovers can be pecuniary, knowledge, and network spillovers, reflecting the different ways value escapes the original inventor. Spillovers do not necessarily imply inaction for the private sector. They do, however, imply market failure to some extent - underinvestment from society's perspective - and should be accounted for when calculating the social rate of return of the R\&D program in question.

The classic approach to appraise economic returns to an investment is the net present value (NPV) (cash flow model) and the related internal rate of return (IRR). The model is expressed by the well-known function

$$
\mathrm{NPV}=\sum_{t=0}^{T} \frac{F_{t}}{(1+r)^{t}},
$$

where $\mathrm{Ft}$ is net cash flow at time $\mathrm{t}$ and $\mathrm{T}$ is the final time period. Link and Scott (2013) summarize a set of seventeen laboratory-based economic impact analyses of this type. While their analytical method arguably has portfolio characteristics - mainly by looking at effects throughout the supply chain rather than just to first tier beneficiaries - it also misses important others such as the explicit evaluation of interdependencies between R\&D projects, of the greater strategic goals, and of effects beyond direct benefit/cost (public R\&D typically has more than one objectives).
A good example of an explicit R\&D portfolio analysis approach is $\mathrm{Na}$ tional Research Council's development and application of an extended NPV methodology to estimate ex ante the net benefits of R\&D projects of the US Department of Energy (NRC, 2005; 2007). This work was mandated by Congress which several years earlier had requested the NRC to produce a series of reports using quantitative indicators to appraise the effectiveness of applied energy R\&D. The first report was a retrospective look of DOE's research on fossil energy and energy efficiency (NRC, 2001).

The most methodologically advanced of these reports (NRC, 2007) used a consistent methodology across six cases of applied energy research portfolios. ${ }^{1}$ The study offered a significant advancement on prior practice by looking at all three perceived primary effects of DOE's programs: (1) to reduce technical risk; (2) to reduce market risk; and (3) to accelerate the introduction of the technology into the marketplace. The methodology uses expert panel reviews of the DOE R\&D programs and estimates the expected economic, environmental, and energy security benefits in three different global economic scenarios. Decision trees are built to describe the technical and market uncertainties and the impact of DOE support in overcoming them. Finally, the acceleration effect was represented either by the change in the likelihood of a project to attain the program goals of completion by a critical date, or by the acceleration of their benefits vis a vis technology developing in the absence of the government program. The overall benefit of the DOE R\&D program is given as the difference between the expected net benefits with DOE support and the expected net benefits without it (counterfactual). The expected benefits correspond to a probability-weighted average of the benefits in specific technical and market outcomes, within common scenarios and under common assumptions. Scenarios were built with the help of NEMS ${ }^{2}$ forecasting the likely energy cost savings through 2030 from the deployment of the new technology generated by the program. The traditional discounted cash flow framework (NPV) was used for these calculations.

Linquiti (2015) has subsequently reevaluated one of those six cases Chemical Industrial Technologies program - pointing out three shortcomings. The first relates to the use of point estimates, rather than a range (probability distribution), for the value of annual energy savings from each new technology. The second is the omission of interdependencies among R\&D projects in the portfolio. ${ }^{3}$ The third shortcoming is the use of the discount rates of $3 \%$ and $7 \%$ suggested by the Office of Management and Budget. The difference between the two is said to constitute a risk premium. As such, it is argued that the use of a $3 \%$ rate can be justified on the basis that public sector program administrators should not exhibit risk aversion. The use of a risk-adjusted discount rate (7\%) is more difficult to justify.

The literature on project selection in the context of institutional R\&D portfolio management is already extensive. ${ }^{4} \mathrm{~A}$ good part of it focuses on the construction of portfolios of projects meeting certain merit criteria. However:

Integrated Gasification Combined Cycle Technology R\&D program; Carbon Sequestration program; Natural Gas Exploration and Production R\&D program; Distributed Energy Resources program; Light-Duty Vehicle Hybrid Technology R\&D program; and Chemical Industrial Technologies program.

2 The National Energy Modeling System (NEMS) of the Energy Information Administration is a comprehensive computer-based system for modeling U.S. energy markets. It projects the production, consumption, imports, and prices of energy, subject to assumptions about macroeconomic and financial factors, world energy markets, resource availability and costs, behavioral and technological choice criteria, cost and performance characteristics of energy technologies, and demographics.

$3 \quad$ The NRC study notes the potential for such interaction.

$4 \quad$ See, for instance, recent accounts in Lo Nigro et al. (2016), Verbano and Nosella (2010), Baker et al. (2015), Vilkkumaa et al. (2015), Zschocke et al. (2014) and references therein. 
"Although rating the individual merit of a project is important, managers are increasingly seeking to maximize the overall value of their research portfolios by bringing the portfolios into alignment with strategic goals. This requires consideration of the relative merits of projects based on the overall capacity being generated by the sum of the combined individual projects. Taking a portfolio approach can also minimize unnecessary duplication of efforts and increase the synergy between inter-dependent projects. Measuring and anticipating these synergies is an exponentially difficult task since it requires a framework for gauging the relational importance of the inputs and outputs for a series of projects while at the same time considering the links between projects and their sub-activities in a portfolio. Projects are typically performed on varying time scales, have varying resource requirements, and have dissimilar goals. For example, some projects may not lead directly to monetary returns but may be invaluable for developing technical competencies and advancing the frontier of knowledge. The important concept to retain is that the combination of all of the individually good projects does not necessarily constitute an optimal portfolio (Chien, 2002)." (Casault et al., 2013a, p. 89)

The idea of R\&D portfolio analysis goes back to principles in finance and, in particular, the idea that assets should not be selected solely on the basis of their individual merits. Markowitz (1952) demonstrated that risks are not additive; neither are returns of financial assets. Evaluation of an asset's return should be in relation to other assets in the portfolio and overall market fluctuations.

$$
E\left(R_{p}\right)=\sum_{i} w_{i} E\left(R_{i}\right)
$$

where $\mathrm{E}$ stands for expectation, $\mathrm{Rp}$ is the return on the portfolio, and wi are weights on individual assets' returns, Ri. The risk associated with individual investments is managed through diversification: portfolio balancing combines assets that will be profitable as a group despite the uncertainties of individual assets and of the overall market. Financial portfolio managers diversify the investments in their portfolio to obtain a predetermined aggregate risk profile.

Much of the basic thinking of financial asset management applies to R\&D project management. Both financial and "real" options give the option holder the right, but not the obligation, to take an action at a future date. Here too one deals with risky investments and uncertain markets. Real options are likely to be valuable when future outcomes are uncertain, there is flexibility to act in the future as the uncertainty is resolved, and the action can increase net benefits (Triantis, 2003). Here too one must consider relationships among projects, which can be both positive or negative (van Bekkum et al., 2009). Here too R\&D project portfolio diversification enables achieving complex - and often conflicting - goals of an R\&D strategy that cannot be attained by any single R\&D project (Eilat et al., 2006).

The result has been the development of a quite extensive literature that has recognized the undervaluation by net cash flow techniques
(NPV) of the managerial flexibility associated with real assets such as technical knowledge. Attempts for enhanced NPV applied in combination with decision trees has gone some way to account for this value as well as for addressing the deficiencies of the NRC work mentioned earlier. Still, there is a strong call for R\&D investments to be analyzed as "real options" (Vonortas and Desai, 2007; Linquiti, 2015) - also including real compound options (Cassimon et al, 2011) - which more recently has been enriched further with an impressive (but still analytically difficult) literature on portfolios of R\&D options. ${ }^{5}$ An important reason for looking at portfolios of options is the realization that the optimal decision under uncertainty is not an average of the optimal decisions under certainty and it is not necessarily near the optimal decision under a core case (Baker et al., 2015). In short:

"... TThe certain absence of risk additivity in all investment portfolios, the frequent absence of return additivity in R\&D portfolios, the value of purposively trading off risk and return, and the complex interaction of investments with conditional payoffs are all persuasive reasons to analyze and value not only individual R\&D projects, but also the R\&D portfolios they comprise." (Linquiti, 2015, p.63-64).

Nonetheless, the application of financial portfolio theory to RqD project analysis is subject to difficulties (Casault et al, 2013a). For one, R\&D projects and their outcomes (underlying assets) are very seldom traded in the market ${ }^{6}$ and there is little information about the project's inherent value and expected future returns (on which the option valuation depends). Relatedly, $R \& D$ projects produce returns that are hard to monetize - the returns may arrive far into the future, they may relate to defense, security of natural resources, improvement of the natural environment, regulation, or reputation. ${ }^{7}$ Monetary returns may not even be an important decision variable for R\&D project selection. For a second, financial assets are typically assumed to behave in a Gaussian manner: expected returns have a defined mean and do not fluctuate much away from it $195.4 \%$ of all measurements will register within $\pm 2 \bigoplus$ from the mean). Casault et al. (2013b) argue that this assumption is likely to be inappropriate for R\&D projects where distinct milestones can greatly influence the expected value of the project. Long tail (large fluctuation) events define the system and cannot be ignored.

\section{MIXED-METHOD APPROACHES TO MODELLING}

In order to account for multiple, difficult to monetize, and often conflicting program and project goals, a diverse set of alternative nonparametric methods to draw up real asset portfolios (including R\&D) have been developed. They have been reviewed time and again in a burgeoning literature on mixed methods for constructing and analyzing R\&D portfolios (Kurth et al., 2017; Gemici-Ozkan et al., 2010) and multi-criteria analyses (Kurth et al., 2017; Linton et al., 2002; Marafon et al., 2015). With multiple goals, the key question is to which extent the implicit prioritization of goals in research portfolios (science supply) fits with perceptions of socioeconomic demands or needs - as captured by experts (Sarewitz and Pielke, 2007). Recent reviews include Verbano and Nosella (2010), Casault et al. (2013a), and Linquiti (2015).

\footnotetext{
5 See, for example, Smit and Trigeorgis (2006), Brosch (2008), Magazzini et al. (2016), Montajabiha et al. (2017), van Bekkum et al. (2009).

$6 \quad$ Financial options are linked to traded financial securities whereas a R\&D option is associated with non-tradeable (in the sense of fixed market prices) knowledge and information.

$7 \quad$ Nonetheless, there have been efforts to monetize such effects. See, for instance, the aforementioned studies of NRC (2005, 2007). Here is a need for further research.
} 
The reader is referred to those sources for detail. Here we offer a summary view of some of the best known methods.

- Peer review score. Classic technique, it involves experts affixing a score on individual projects against a series of merit criteria. Projects are then rank ordered and the top projects selected. Despite serious deficiencies in systematic portfolio formulation, the process is useful in early stage activities ensuring the quality of projects that may form a portfolio.

- Analytic Hierarchy Process (AHP). Technique to organize and analyze complex input from various sources. It helps structure a problem in terms of various quantifiable elements organized logically so that they can be measured against overall goals and alternative solutions. A hierarchy is structured starting with an overall project objective at the highest level that is decomposed into a series of uncorrelated criteria which can be further decomposed into a series of sub-criteria on as many levels as required by the problem. The lowest hierarchical level describes a series of alternative solutions for completing the criteria immediately above. Evaluation based on pairwise comparisons by experts which can be processed mathematically to determine overall project "efficiency". AHP is better viewed as an input to support decision making. It can be followed by a second optimization process for the overall portfolio.

- Data Envelopment Analysis (DEA). Non-parametric methodology to estimate a frontier by estimating the relative efficiency of a number of producers. Efficiency is defined as the ratio of the sum of weighted outputs to the sum of weighted inputs. Advantages include avoidance of specifying mathematical functions and ability to compare quantitative and qualitative factors. The technique can also deal with a portfolio of projects with or without interactions.

- Balance Scorecard (BSC). A model for analyzing strategy and performance information for all types of organizations (Kaplan and Norton, 1992). Widely adopted in the private sector to plan and align strategic initiatives, clarify and translate vision and strategy into action, and enhance strategic feedback and learning. The technique purports to provide a balance between (1) short- and long-term objectives; (2) financial and non-financial measures; (3) lagging and leading indicators; and (4) internal and external performance perspectives. Weaknesses include complexity of performance measurement, judgement biases, and the need to reach some synthetic metric that summarizes the whole set of multiple perspectives and indicators into success or failure. Multi-criteria decision-making frameworks are an appropriate approach to untangling these complexities in performance evaluation and decision-making

Most of the techniques used by practitioners have been hybridized to help provide richer pictures of portfolios than any single technique. For instance, Eilat et al. (2006) combined BSC with DEA to establish a methodology to evaluate alternative portfolios of projects in order to choose the best combination. In another example, Kim et al. (2016) combined AHP and BSC to analyze the strategic fit of portfolio of national R\&D programs with R\&D policies.

\section{RESEARCH PORTFOLIO AS A HEURISTIC FOR MANAGING RESEARCH PRIORITIES}

There are growing concerns that research needs to become more responsive to societal needs and demands (Sarewitz and Pielke, 2007; Bozeman and Sarewitz, 2011). Posed in simple terms, the question is: "Are we doing the right type of science given current societal needs?" The answer to this question is often highly critical, as illustrated by widespread debate generated by Sarewitz' article in The New Atlantis in 2016: although research does contribute to wellbeing, it could be better aligned with societal needs or demands. Some empirical studies in health support the claims of misalignment (e.g. in prioritisation across diseases as shown by Evans et al., 2014 or Yegros and Rafols, 2018).

In order to improve alignment between research and societal needs, public $R \& D$ agencies have put in place a variety of initiatives for priority setting, such as grand challenges (Hicks, 2016) and participatory processes for setting research agendas (e.g. in health, the UK-based James Lind Alliance $^{8}$, or nationally in the Netherlands ${ }^{9}$ ). In this broader and more political discussions on priority setting, given high uncertainty and lack of value consensus (ambiguity), R\&D portfolio analysis serves different purposes and requires different management strategies.

\subsection{RGD PORTFOLIO ANALYSIS UNDER CONDITIONS OF HIGH UNCERTAINTY AND AMBIGUITY}

The quantitative techniques and mixed-methods for portfolio modelling presented earlier are useful for applied research in conditions in which there is a reasonable understanding of the potential outcomes of projects and in which value or goal disagreements regarding priorities are relatively minor. In the context of research that is not applied downstream, making estimates of project success in the face of multiple and ambiguous goals becomes very difficult.

There are two types of limitations regarding knowledge, as illustrated in Figure 1, following Stirling and Scoones (2009). On the one hand, there is the uncertainty about possibilities of research success in achieving the expected goals. When the probabilities of success can be estimated, as in finance, one can use the concept of 'risk', meaning that there is some statistical information about expectations of success and portfolio modelling is possible. Under conditions of multiple, but well-defined goals (shifting towards the right to 'Ambiguity'), mixed methods such as Peer Review Score or Data Envelopment Analysis can be helpful. However, when probabilities cannot be estimated we should stay with the notion of 'uncertainty'. On the other hand, there is the ambiguity, or lack of knowledge, or lack of agreement regarding the goals of a project, particularly in the very common situations of public R\&D in which there are multiple goals. In summary, under conditions of high ambiguity and/or high uncertainty, modelling becomes problematic. 


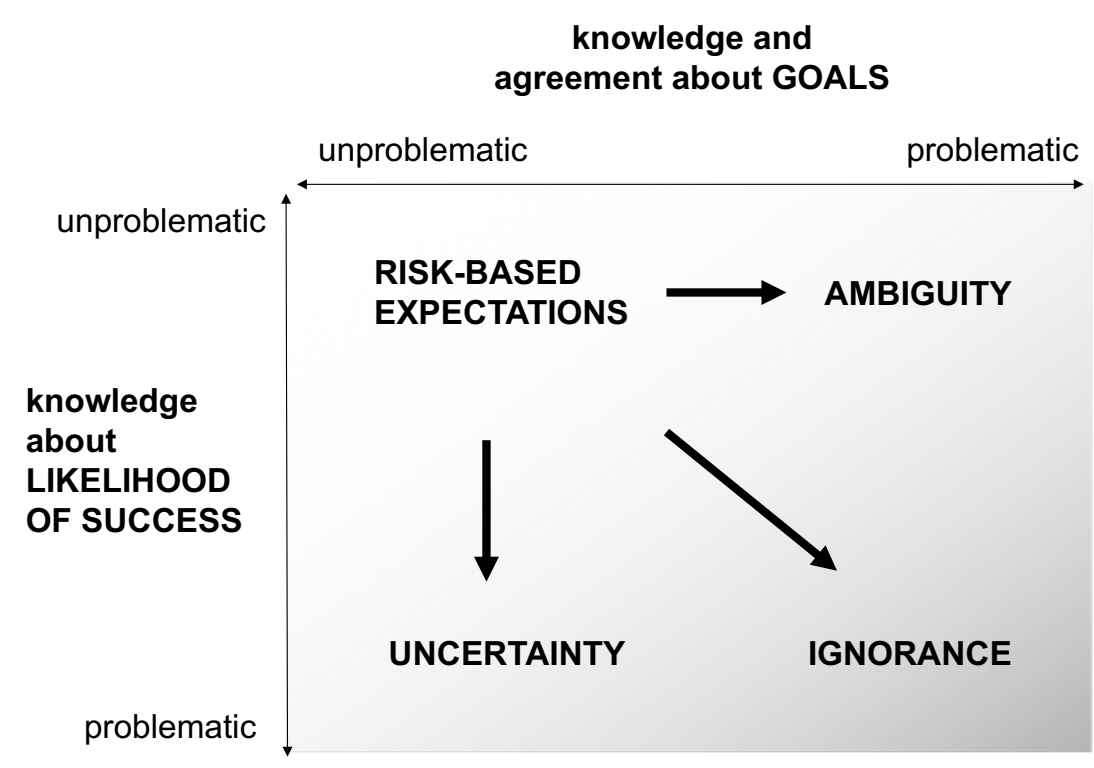

Figure 1. Types of knowledge limitations in relation to project management. Source: Adapted from Stirling and Scoones (2009).

Under these conditions of ambiguity and contested nature of the goals (given multiple desirable outcomes) and high uncertainty, the analogy with the financial portfolios breaks down to a large extent (Wallace and Rafols, 2015). The techniques reviewed in section 2 of portfolio modelling can still play an important role at illuminating the value of diversity and seeking positive interactions or complementarity between projects in resource allocation. However, under uncertainty and ambiguity R\&D portfolio analysis can be particularly helpful as a tool to coordinate collective reflexivity on the goals and the expected outcomes of research programs. For example, in agreement with calls for mapping the public values of research (Bozeman and Sarewitz, 2011) and responsible innovation (Stilgoe et al. 2013), R\&D portfolios are explored by the UK BBSRC ${ }^{10}$ as a means to foster "anticipation, inclusion, reflexivity and responsiveness" in research management through participatory processes (Smith et al., 2016).

The opening up of portfolio analysis to a broader set of participants from scientific experts and policy maker to wider forms of expertise and lay people - is consistent with Pielke's (2007) view that under conditions in of high uncertainty and lack of value agreement, one cannot separate analysis and decision-making as two separate, consecutive processes. Since technical assumptions used in modelling analyses can depend experts' values and can be biased towards quantifiable evidence, portfolio analysis should ideally be examined by diverse stakeholders bringing in contrasting perspectives on uncertainties and ambiguities. In this way, it is possible to build-up evidence-based policy making while trying to include those sources of evidence that are less quantifiable, formalized or institutionalized (Saltelli and Giampetro, 2017).

\subsection{COMPARING SCIENCE SUPPLY AND SOCIETAL NEEDS}

There can be many heuristics or strategies for mixed-methods or qualitative analysis of research portfolios depending on the goals, organizations and contexts of the research programs. In general, it involves the comparison of the composition of a portfolio (science supply) with the distribution of desired or expected outcomes (societal needs).

Hage et al. (2007) provide a useful and pragmatic framework to qualitatively assess the composition of a portfolio. The key questions to be posed are: "Where to invest? What capabilities are needed and where? Which coordination mechanism should be used and where?". Building up capabilities for a certain portfolio focus involves thinking about the personal skills and technological instruments needed and providing training programs, whether new kinds of organizations or coordination activities are needed (e.g. new technology platforms). Emphasis in capabilities reminds us that societal impact is often not achieved directly through the research carried out, but through the capabilities created, particularly in terms of human resources (Bozeman and Rogers 2001).

In portfolios for issues around large scale societal problems or grand challenges, it will be particularly important to pay attention to coordination mechanisms between different arenas of research - whether more basic, applied, commercialization, etc. The ensemble of programs or policy actions within a given R\&D portfolio can be thought as the 'policy mix' that will implement it (Flanagan, Uyarra and Laranja, 2011). 


\section{Appraisal of science supply}

The first and paramount question to be addressed in portfolio management is 'Where to Invest'. The contents within an R\&D portfolio, which will define the options or choices to be made, can be understood from different perspectives. Typically, they are defined in terms of disciplines, technologies, application or problems (Hage et al., 2007; p. 733). The choice of the specific perspectives used is very important as it will determine the type of priority setting, e.g. whether the choice is among disciplinary topics or among types of problems. Once a perspective is chosen with type of classifications (or 'ontologies') that describe the portfolio, the next step is to explore the distribution of research over categories, for example with a cognitive map or research landscape, as illustrated in Figure 2. This allows to begin asking questions such as Where are there gaps? Where a small investment can make a noticeable impact? (Hage et al., 2007, p. 734).

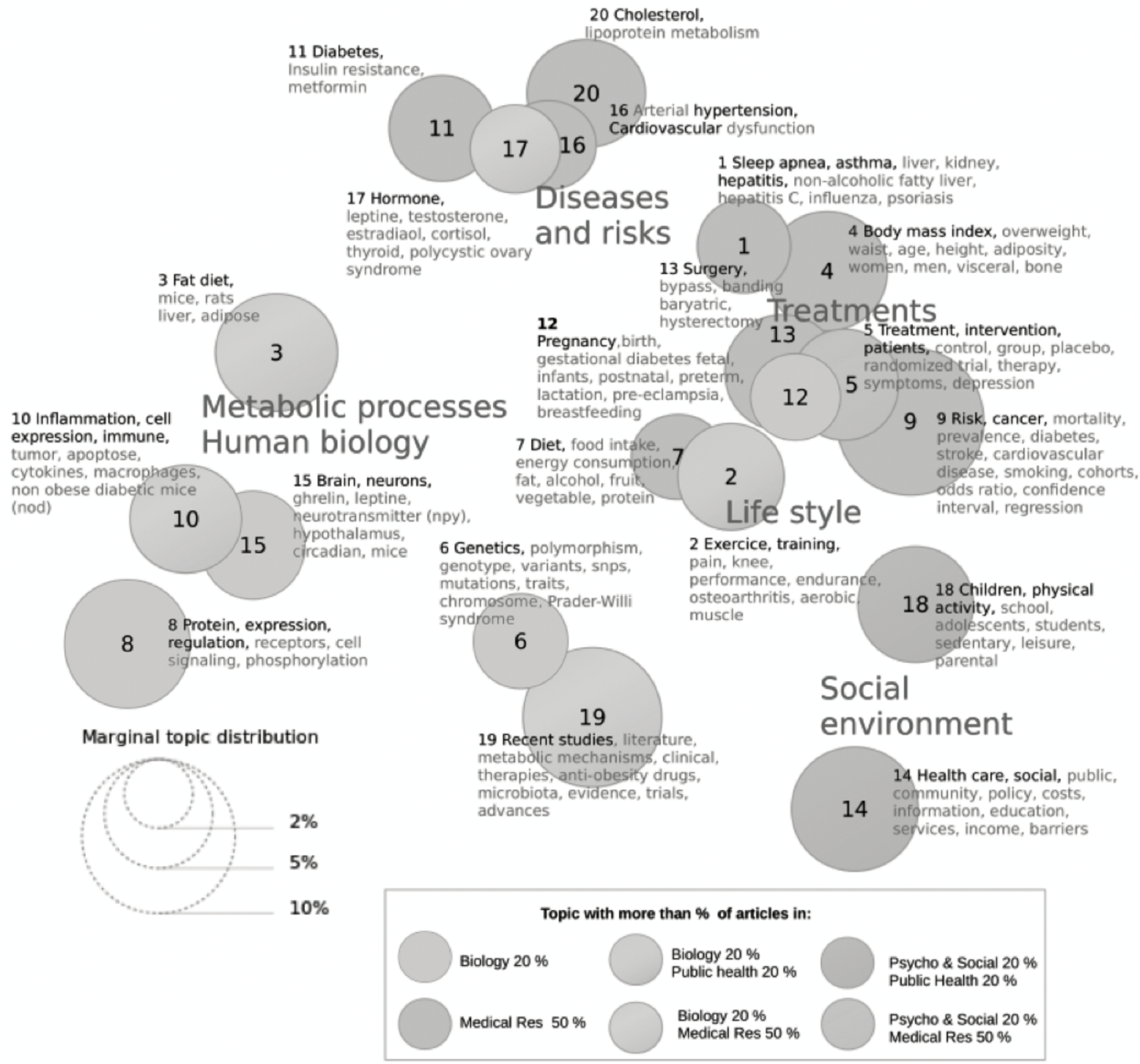

Figure 2. Relative distribution of publications related to obesity over various topics.

Source: Cassi et al. (2017).

Note: This figure illustrates the research landscape of obesity. The obesity portfolio of a given funding agency is defined by its distribution of topics over this landscape. The size of the circles is proportional to the number of publications in a given topic. Colours indicate main disciplines: basic biology (green, left), medical research (orange, top), public health and social sciences (purple, bottom right). 
Improvements in data availability, data processing and science mapping have resulted in major advances in research portfolios visualization facilitating the task of portfolio mapping. These advances are detailed in Section 4 below. Although these new techniques are very helpful, they rely on decisions on classifications which often have important effects yet are poorly understood. It is thus important to keep a critical eye on classification schemes used.

\section{Appraisal of societal needs or demands}

The other key issue is to map societal needs or preferences about expected research outcomes. This is possibly the most challenging factor in portfolio management. Generally, there is no quantitative information about societal needs. Health is an important exception since one can use public estimates on burden in terms of years lost due to disease (e.g. DALYs Disability Adjusted Life Years) or in terms of labor or healthcare costs (Evans et al., 2014; Yegros and Rafols, 2018). Increasing availability of digital healthcare (big) data is quickly enhancing the possibility of making more fine-grained estimates of health needs. For example, the NIH shows the comparison between its research expenditure and disease burden in a dedicated webpage. ${ }^{11}$ Also in the case of agriculture, one can make exploratory estimates of 'revealed demands' on the bases of data on crop exports, imports, cultivated area, food consumption or processing, and crop use in animal feed (Nature Plants, 2015; Ciarli and Rafols, 2017).

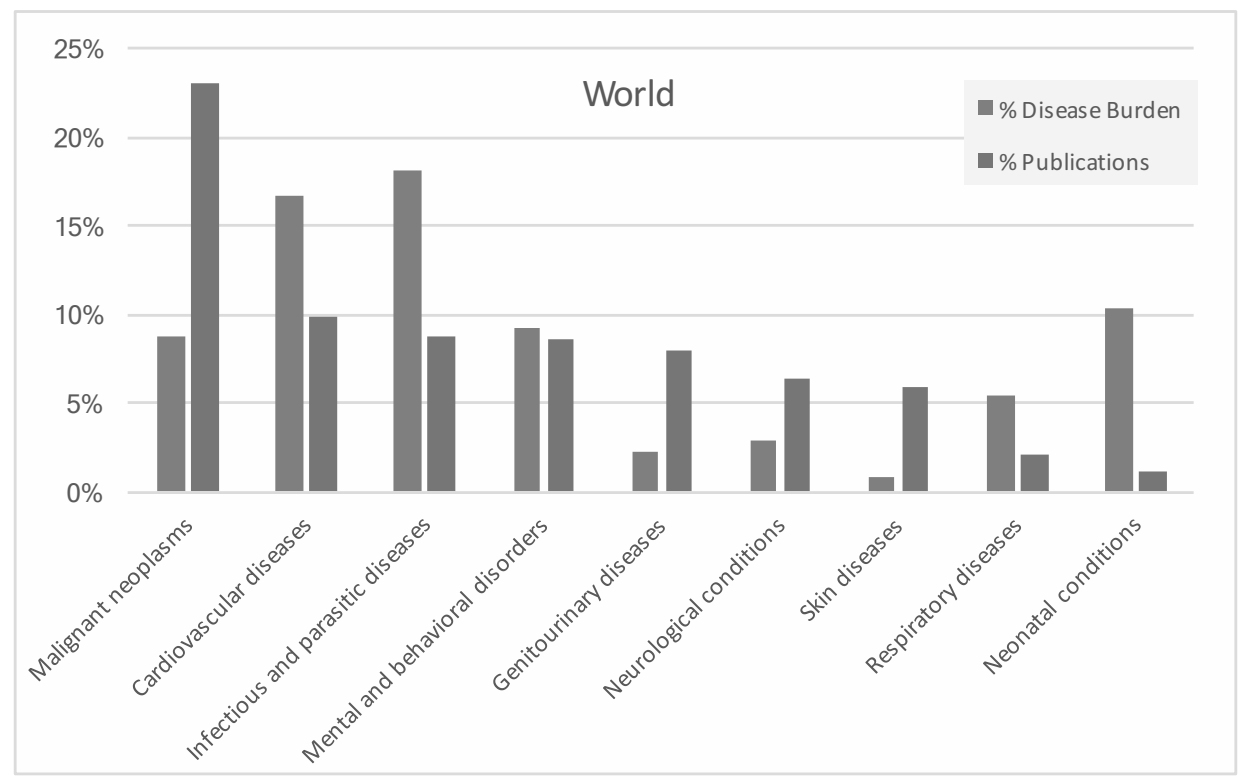

Figure 3. Comparison between relative disease burden and associated research output for the world.

Source: Yegros and Ràfols (2018).

Note: Percentage of disease burden (in blue, left) is based on WHO estimates in terms of Disability Adjusted Life Years (DALYS). Percentage of research outputs per disease (in red, right) are estimated from Web of Science publications using as disease classification MEDLine's Medical Subject Headings. Only selected categories are shown.

In the absence of data on societal needs or demands one alternative is to use scoring and multi-criteria methods such as those listed in Section 2.2. However, recent science policy initiatives point towards the importance of deliberative processes with a wide participation of stakeholders (e.g. the agenda developed by the EC Scientific Panel for Health ${ }^{12}$ ). The UK James Lind Alliance ${ }^{13}$ is an example of a program of stakeholder engagement in priority setting of health needs for specific diseases.

In summary, there are now established and complementary methods - including institutional data, mixed approaches such as multi-criteria methods, and stakeholder deliberation - for making estimates of societal needs and preferences regarding research outcomes, even if results may always be interpreted as controversial.

\subsection{IMPLEMENTING PROCESSES OF RGD PORTFOLIO APPRAISAL}

R\&D portfolio analysis can be used as a heuristic tool to appraise research priorities against societal needs or demands. It should be noted that the perspective on research portfolios focuses at program level within agencies, institutes or divisions.14 Various agencies are already using technical tools of portfolio analysis for reporting and information purposes, generally based on publication and funding data. However, R\&D portfolio analysis requires not only various technical efforts, but institutional learning at implementation (Hellström et al., 2017).

On the basis of an experience in the UK BBSRC, Robert Smith and colleagues (2016) propose four management stages for implementing

11 https://report.nih.gov/info_disease_burden.aspx

12 https://ec.europa.eu/programmes/horizon2020/en/h2020-section/scientific-panel-health-sph

13 Established in 2004 and is supported by the UK National Institute of Health Research http://www.jla.nihr.ac.uk/

14 The distribution of resource across at higher levels shaped by political processes of budget allocation across agencies or divisions, is beyond the scope of this study. 
portfolio deliberation participation in funding agencies. The first phase involves clarifying the aim and scope of stakeholder participation. The second phase mobilizes internal human resources in the agency in order to understand the scientific topics of the portfolios and the expected societal outcomes. The third phase involves a critical analysis of the knowledge base, while phase four identifies the stakeholders to participate. The deliberation process can follow methods thoroughly tested in engagement practices.

During the process of portfolio analysis aimed at funding, one should also be aware that public funding is only one of the determinants of $d e$ facto research priorities. Other factors having major influences include private funding, preferences (biases) implicit in research evaluation, and institutional goals, particularly in mission-oriented organizations funded via block grants (such as health research centers or agriculture institutes) (Wallace and Rafols, 2016).

\section{DATA AVAILABILITY, PROCESSING AND VISUALIZATION OF PORTFOLIOS}

Government policies of data transparency and accountability as well as technical advances in data availability, processing, classification and visualization are progressively facilitating the quantitative analysis of research portfolios. However, these developments are still in early phase and portfolio analysis has yet to overcome some technical hurdles. For example, a report by the Rathenau Institute notices that:

"One of the most important initial results of this study was our observation that there is a major shortage of hard data on the allocation of research funding. That shortage makes it virtually impossible to develop informed policy, estimate policy effects and know whether the priorities set by a funding body will have an impact." (Koier et al, 2016, p.11)

In spite of these difficulties, the technical support for portfolio anaIysis is quickly advancing. We present below developments in terms of data availability, processing and visualization following the steps in knowledge domain analysis (Borner, Chen and Boyack, 2003, p. 189).

\section{Data availability and infrastructure}

Knowledge infrastructure of project funding is now publicly available and keeps improving. US StarMetrics ${ }^{15}$ (with Federal Reporter) or the UK Gateway to Research ${ }^{16}$ contain details of publicly funded research, allowing large scale analysis of the performers, the contents and the contexts of research projects. Data providers such as the Web of Science now include acknowledgement of publications since 2009, though the data is based on self-reporting and has limitations (Costas and Van Leeuwen, 2012). Information services analysing these data are now being offered by academic analysts (e.g. at universities in Indiana, Leiden, or Montréal) and consultancies (e.g. ChalkLabs, SciTech Strategies and Uber Research). Funding agencies such as the NIH are creating internal information infrastructure and capabilities to manages portfolios (Srivastava et al., 2007; Haak et al., 2012).

\section{Data processing and classifications}

Data processing and classification is often the most opaque technical step in portfolio analysis. However, it deserves careful attention since the use of specific classification schemes and the subsequent categorization of projects has major implications. Large scale disciplinary classifications are based on journal classifications offered by data providers such as the Web of Science or Scopus, which show important differences (Rafols, Porter and Leydesdorff, 2010). In the last decade, more fine-grained and thematically accurate classifications based in article-level classifications have been developed (Waltman and Van Eck, 2012; Klavans and Boyack, 2017). However, these classifications rely on citation data and are thus problematic for grants. Co-word maps (Ciarli and Rafols, 2017) and new semantic algorithms, such as topic modelling (Blei, 2012), allow the construction of research landscapes and portfolios using only text (e.g. Cassi, 2017). The robustness of these semantic methods is yet open to debate (Leydesdorff and Nerghes, 2017).

\section{Visualizations}

Novel visualisation techniques greatly facilitate the portrayal of cognitive landscape and social networks in which the projects of portfolios are embedded. The literature is rife with examples of visualization techniques which offer a portfolio view of projects (see Börner's scimaps. org), as visualization tools such as VOSviewer or Gephi become easier to use. These maps are useful for mapping purposes - portfolio spread and an overall picture of the relationship to strategic research objectives of the institution - which, in turn, are more consistent with how decision makers conceptualize qualitative traits in their own judgement. Weaknesses include the potential lack of stability of visualization and that these techniques do not generally address portfolio-level issues such as project or thematic relationships and synergies, although it is feasible (e.g. Rafols et al. 2012).

\section{CONCLUDING REMARKS}

The use of research portfolios in science and innovation policy depends on the type of research and policy context. In cases where there is manageable degree of uncertainty and some value consensus, one can apply modelling techniques. In cases, with high uncertainty and lack of consensus on agreement on goals, portfolio analysis can feed into and enrich qualitative processes of priority setting.

A set of conclusions emerges from our discussion on R\&D portfolio modeling:

1. It is feasible to estimate the risk and potential return of applied R\&D projects. However, discounted cash flow methods (NPV) are increasingly recognized as inadequate in characterizing public applied R\&D investments, much as they have been recognized in the private sector for some time now. Alternative methods such as 'real options' allow better appraisal of the value of R\&D management flexibility in the presence of risk and of the differential effects on each R\&D project depending on the level of risk and the size of the upside payoff. 
2. Accepting that both risk and return are important compels the use of portfolio-level analysis. Risk is not additive. Frequently the returns of R\&D projects are not additive. Absent portfolio analysis there is no way to discern the overall risk and overall return of a set of R\&D investments.

3. Portfolio analysis requires the explicit evaluation of the relationship between individual R\&D projects. Both technical connections and market connections are important. One can think, for example, of the opportunity to share results and the possibility of economies of scope across projects. Inter-project relationships affects the risk of the overall R\&D portfolio. Furthermore, managers may also consider the possibility of non-obvious "deep" connections through independent variables (e.g., energy prices).

4. Public R\&D programs typically have multiple objectives (ambiguity). In order to account for multiple, difficult to monetize, and often conflicting program and project goals, a diverse set of alternative mixed methods to draw up real asset portfolios (including R\&D) have been developed. These methods can stand on their own bottom; they can be combined with economic quantitative approaches for addressing portfolio optimality.

Using research portfolios as a heuristic for managing research priorities leads to complementary insights:

5. In R\&D programmes characterised by multiple objectives, mixed methods for exploring ambiguities in goals and uncertainties in outcomes can be used as part of wider participatory and/or deliberative processes for priority setting in funding agencies.

6. These broader priority setting practices require not only the development of technical expertise, but also institutional learning for managing processes of deliberation and integration of diverse knowledge sources.

7. In recent years there has been a rapid increase in data sources that facilitate portfolio analysis of science supply in terms of funding and publication data, classification schemes and visualization techniques. However, attention must be paid to adapt data management to portfolio goals and contexts - especially the analytical categories (classifications) used.

8. Expected outcomes of portfolios can be compared with estimates of societal needs or demands. These estimations are very challenging. Increasing data availability in sectors such as health, agriculture and sustainability allows to develop new estimates of the societal needs addressed by research programs. Mixed method approaches can assess the diversity of views of stakeholders.

9. Novel data and visualizations of portfolio outputs (science supply) together with new data and methods for assessing societal needs (demand) can improve priority setting processes, in particular facilitating the participation of stakeholders in deliberations.

Our policy recommendations in short:

i. Use of portfolio methods for R\&D program appraisal is generally recommended.

ii. Modeling of research portfolios is recommended for cases of agreement on program goals where value estimates are possible (presence of risk, low uncertainty)

iii. Portfolios can also be a useful tool to assist in deliberative processes aimed at aligning science supply with social needs or demands for cases without agreement on program goals, and when uncertainty is rampant.

Finally, while not treated explicitly in this report due to space limitations, "big data" exploiting unconventional sources of information may hold a big promise in terms of estimating not easily monetized goals of public R\&D programs, thus deserving research attention.

Acknowledgements. The authors thank the participants of the "Workshop on Government Decision-Making to Allocate Scientific Resources" organized by the Innovation Policy Forum of the US National Academies in Washington, DC, January 8-9, 2018, for useful comments and recommendations. We also would like to thank several interviewees for opinions on the use of portfolio analysis in funding agencies. Both authors acknowledge funding support by NSF's Science for Science and Innovation Policy program. All remaining errors and misconceptions are ours.

\section{REFERENCES}

Baker, E., Olaleye, O. and Reiss, L. A. (2015). Decision Frameworks and the Investment in R\&D, Energy Policy, 80: 275-285.

Blei, D. M. (2012). Probabilistic topic models. Communications of the ACM 55(4): 77-84.

Borrás, S. and C. Edquist (2014). Innovation Policy for Knowledge Production and R\&D: the Investment Portfolio Approach, Papers in Innovation Studies, Paper no. 2014/21. CIRCLE, Lund University.

Börner, K., Chaomei C. and Boyack, K. W. (2003). Visualizing knowledge domains. Annual review of information science and technology 37.1 (2003): 179-255.

Börner, K., Klavans, R., Patek, M., Zoss, A. M., Biberstine, J. R., Light, R. P., ... and Boyack, K.W. (2012). Design and update of a classification system: The UCSD map of science. PloS one 7.7 (2012): e39464.

Bozeman, B. and J. Rogers (2001). Strategic management of government-sponsored R\&D portfolios. Environment and Planning C: Government and Policy, 19:413-442.

Bozeman, B., and D. Sarewitz (2011). Public Value Mapping and Science Policy Evaluation. Minerva 49(1): 1-23. doi:10.1007/s11024-011-9161-7.

Brosch, R. (2008). Portfolios of Real Options, Springer.

Cassi, L., Lahatte, A., Rafols, I., Sautier, P. and Turckheim, É. De. (2017). Improving fitness :Mapping research priorities against societal needs on obesity. Journal of Informetrics, 11(4), 1095-1113. https://doi. org/10.1016/j.joi.2017.09.010

Ciarli, T. and Rafols, I. (2017). The Relation between Research Priorities and Societal Demands: The Case of Rice. Available at SSRN: https://ssrn. com/abstract $=3093285$ 
Casault, S., Groen, A. J. and Linton, J. D. (2013a). Selection of a Portfolio of R\&D Projects, in Link, A. N. and Vonortas, N. S. (eds) Handbook on the Theory and Practice of Program Evaluation, Edward Elgar.

Casault, S., Groen, A. J. and Linton, J. D. (2013b). Examination of the Behavior of R\&D Returns Using a Power Law, Science and Public Policy, 40: $219-228$.

Cassimon, D., De Backer, M., Engelen, P. J., Van Wouwe, M. and Yordanov, V. (2011). Incorporating Technical Risk in Compound Real Option Models to Value a Pharmaceutical R\&D Licensing Opportunity, Research Policy, 40:1200-1216.

Costas, R., and van Leeuwen, T.N. (2012). Approaching the "reward triangle": General analysis of the presence of funding acknowledgments and "peer interactive communication" in scientific publications. Journal of the American Society for Information Science and Technology, 63(8): 1647-1661. https://doi.org/10.1002/asi.22692

Eilat, H., Golany, B. and Shtub, A. (2006). Constructing and Evaluating Balanced Portfolios of R\&D Projects with Interactions: a DEA Based Methodology, European Journal of Operational Research, 172(3): 1018-1039.

Evans, J. A., Shim, J. M. and Ioannidis, J.P. (2014). Attention to local health burden and the global disparity of health research, PLoS One, 9(4): e90147.

Flanagana, K., Uyarra, E. and Laranja, M. (2011). Reconceptualising the 'policy mix' for innovation. Research Policy 40:702-713. doi:10.1016/j. respol.2011.02.005

Gemici-Ozkan, B., Wu, S. D., Linderoth, J. D. and Moore, J. E. (2010). R\&D Project Portfolio Analysis for the Semiconductor Industry, Operations Research, 58(6): 1548-1563.

Haak, L. L., Ferriss, W., Wright, K. Pollard, M. E., Barden, K., Probus, M. A., Tartakovsky, M. and Hackett, C. J. (2012). The electronic Scientific Portfolio Assistant: Integrating scientific knowledge databases to support program impact assessment. Science and Public Policy 39: 464-475. doi:10.1093/scipol/scs030.

Hage, J., Jordan, G. and Mote, J. (2007). A theory-based innovation systems framework for evaluating diverse portfolios of research, part two: macro indicators and policy interventions. Science and Public Policy, 34(10): 731-74.

DOI: $10.3152 / 030234207 \times 265385$

Hellström, T., Jacob, M. and Sjöö, K. (2017). From thematic to organizational prioritization: the challenges of implementing RDI priorities. Science and Public Policy 44(5):599-608.

Hicks, D. (2016). Grand Challenges in US science policy attempt policy innovation. International Journal of Foresight and Innovation Policy 11.13 (2016): 22-42.

Interagency Task Group on Science Policy (2008), The Science of Science Policy, Report to the Subcommittee on social, Behavioral and
Economic Sciences, Committee on Science, US National Science and Technology Council, Office of Science and Technology Policy.

Kim, J., Jo, H., Kim, Y. and Jeon, J. (2016). Managing the Strategic Fit of National R\&D Programme Portfolios: The Case of Creative Economy Policy in Korea, Innovation: Management, Policy \& Practice, 18(2): 99144.

Klavans, R. and Boyack, K. W. (2017). Which type of citation analysis generates the most accurate taxonomy of scientific and technical knowledge? Journal of the Association for Information Science and Technology 68.4 (2017): 984-998.

Koier, E., van der Meulen, B., Horlings, E. and Belder, R. (2016). Spinning plates - Funding streams and prioritisation in Dutch university research. The Hague, Rathenau Instituut 2016. Available at https://www. rathenau.nl/en/news/spinning-plates-funding-streams-and-prioritisation-dutch-university-research.

Kurth, M. H., Keisler, J. M., Bates, M. E., Bridges, T. S.,Summers, J. and Linkov, I. (2017). A Portfolio Decision Analysis Approach to Support Energy Research and Development Resource Allocation, Energy Policy, 105: 128-135.

Kurth, M. H., Larkin, S., Keisler, J. M. and Linkov, I. (2017). Trends and Applications of Multi-Criteria Decision Analysis: Use in Government Agencies, Environment Systems \& Decisions, 37(2): 134-143.

Leydesdorff, L. and Nerghes, A. (2017). CoĐword maps and topic modelling: A comparison using small and mediumĐsized corpora $(\mathrm{N}<$ 1,000). Journal of the Association for Information Science and Technology 68(4): 1024-1035.

Link, A. N. and Scott, J. T. (2013). The Theory and Practice of PublicSector R\&D Economic Impact Analysis, in Link, A. N. and Vonortas, N. S. (eds) Handbook on the Theory and Practice of Program Evaluation, Edward Elgar.

Linquiti, P. D. (2015). The Public Sector RqD Enterprise: A New Approach to Portfolio Evaluation, Palgrave-Macmillan.

Linton, J. and Vonortas, N. S. (2015). From Research Project to Research Portfolio: Meeting Scale and Complexity, Foresight and STI Governance, 9(2): 38-43.

Linton, J., Walsh, S. T. and Morabito, J. (2002). Analysis, Ranking and Selection of R\&D Projects in a Portfolio, R\&D Management, 32(2): 139-148.

Lo Nigro, J., Morreale, A. and Abbate, L. (2016). An Open Innovation Decision Support System to Select a Biopharmaceutical R\&D Portfolio, Managerial and Decision Economics, 37: 392-406.

Luehrman, T. A. (1998). Strategy as a Portfolio of Real Options, Harvard Business Review, September-October. 
Magazzini, L., Pammolli, F. and Riccaboni, M. (2016). Real Options and Incremental Research in Pharmaceutical R\&D Project Portfolio Management, Creativity and Innovation Management, 25(2): 292-302.

Marafon, A. D., Ensslin, L., Rde Oliveira Lacerda, . T. and Ensslin, S. R. (2015).The Effectiveness of Multi-Criteria Decision Aid Methodology: A Case Study of R\&D Management, European Journal of Innovation Management, 18(1): 86-109.

Markovitz, H. (1952) "Portfolio Selection", Journal of Finance, 7(1): 77-91.

Markowitz, H. and Markowitz, H.M. (1991). Portfolio Selection: Efficient Diversification of Investments, Cowles Foundation for Research in Economics at Yale University, Blackwell.

Meier, F. and Schimank, U. (2010). Mission Now Possible: Profile-Building and Leadership in German Universities. In R. Whitley, J. Gläser, \& L. Engwall (Eds.), Reconfiguring Knowledge Production. Changing Authority Relationships in the Sciences and their Consequences for Intellectual Innovation. (pp. 2011-2236). Oxford: Oxford University Press.

Montajabiha, M., Khamseh, A. A. and Afshar-Nadjafi, B. (2017) A Robust Algorithm for Project Portfolio Selection Problem Using Real Options Valuation, International Journal of Managing Projects in Business, 10(2): 386-403.

National Research Council (2007). Prospective Evaluation of Applied Energy Research and development at DOE (Phase Two), Committee on Prospective Benefits of DOE's Energy Efficiency and Fossil Energy R\&D Programs, Board on Energy and Environmental Systems, Division on Engineering and Physical Sciences, Washington, DC: National Academies Press.

National Research Council (2005). Prospective Evaluation of Applied Energy Research and development at DOE (Phase One): A First Look Forward, Committee on Prospective Benefits of DOE's Energy Efficiency and Fossil Energy R\&D Programs, Board on Energy and Environmental Systems, Division on Engineering and Physical Sciences, Washington, DC: National Academies Press.

National Research Council (2001). Energy Research at DOE: Was It Worth It?, Washington, D.C.: National Academy Press.

Nature Plants Editorial (2015). Neglected tropical crops. Nature Plants. doi: 10.1038/NPLANTS.2015.204

Pielke, R. A. (2007). The honest broker. Making sense of science in policy and politics. Cambridge: Cambridge University Press.

Rafols, I., Porter, A.L. and Leydesdorff, L.(2010). Science overlay maps: a new tool for research policy and library management, Journal of the American Society for Information Science and Technology, 61(9):1871-1887.

\section{Rafols, I., Leydesdorff, L., O'Hare, A., Nightingale, P. and Stirling, A.} (2012). How journal rankings can suppress interdisciplinary research: A comparison between Innovation Studies and Business \& Management, Research Policy, 41: 1262-1282. doi: 10.1016/j.respol.2012.03.015
Ruegg, R. (2006). Bridging from Project Case Study to Portfolio Analysis in a Public R\&D Program: A Framework for Evaluation and Introduction to a Composite Performance Rating System, Economic Assessment Office, Advanced Technology Program, National Institute of Standards and Technology, U.S. Department of Commerce, Gaithersburg MD (NIST GCR 06-891).

Ruegg, R. (2007). Quantitative Portfolio Evaluation of US Federal Research and Development Programs, Science and Public Policy, 34(10): 723-730.

Salter, A. J., and Martin, B. R. (2001). The economic benefits of publicly funded basic research: A critical review. Research Policy 30: 509-532. doi:10.1016/S0048-7333(00)00091

Saltelli, A. and Giampietro, M. (2016). What is wrong with evidence based policy, and how can it be improved? Futures. https://doi. org/10.1016/j.futures.2016.11.012

Sarewitz, D. and Pielke Jr., R. A. (2007). The neglected heart of science policy: Reconciling supply of and demand for science, Environmental Science \& Policy 10: 5-16. doi:10.1016/j.envsci.2006.10.001.

Schilling, M. A. (2017). Strategic Management of Technological Innovation, New York, NY: McGraw-Hill Education (5th ed).

Srivastava, C. V., Deshmukh Towery, N. and Zuckerman, B. (2007). Challenges and opportunities for research portfolio analysis, management, and evaluation, Research Evaluation 16: 152-156. doi:10.3152/095820207X236385.

Smit, H. T. J. and Trigeorgis, L. (2006). Strategic Planning: Valuing and Managing Portfolios of Real Options, R\&D Management, 36(4): 403-419.

Smith, R.D.J., Hartley, S., Jewitt, T. and Middleton, P. (2016). Integrating diverse knowledges into research funding organisations: consequences for operationalising responsible innovation. Paper presented in the 4S Conference, Barcelona 2016. Journal version to be available soon. See also report of the study. Available at https://kclpure.kcl.ac.uk/portal/ files/48727275/KITo_v1_0.pdf

Stilgoe, J., Owen. R. and Macnaghten, P. (2013). Developing a framework for responsible innovation, Research Policy 42:1568- 1580. http:// dx.doi.org/10.1016/j.respol.2013.05.008

Triantis, A. (2003). Real Options, in Logue D. and Seward J. (eds) Handbook of Modern Finance, New York, NY: Research Institute of America (p. D1-D32).

Van Bekkum, S., Pennings, E. and Smit, H. (2009). A Real Options Perspective on R\&D Portfolio Diversification, Research Policy, 38: 11501158.

Van Eck, N. J., and Waltman, L. (2014). Visualizing bibliometric networks. In Measuring scholarly impact (pp. 285-320). Springer International Publishing. 
Verbano, C. and Nosella, A. (2010). Addressing R\&D Investment Decisions: A Cross-Analysis of R\&D Project Selection methods, European Journal of Innovation Management, 13(3): 355-380.

Vilkkumaa, E., Salo, A., Liesio, J. and Siddiqui, A. (2015). Fostering Breakthrough Technologies - How Do Optimal Funding Decisions Depend on Evaluation Accuracy?, Technological Forecasting \& Social Change, 96: 173-190.

Vonortas, N. S. and Desai, C. (2007). Real Options Framework to Assess Public Research Investments, Science and Public Policy, 34(10): 699-708.

Wallace, M. L. and Rafols, I. (2015).Research Portfolio Analysis in Science Policy: Moving from Financial Returns to Societal Benefits, Minerva, 53(2): 89-115.

Wallace, M. L. and Rafols, I. (2017). Shaping the agenda of a grand challenge: Institutional mediation of priorities in avian influenza research. Available at SSRN: http://papers.ssrn.com/sol3/papers.cfm? abstract_id=2699844

Waltman, L. and Eck, N. E. (2012). A new methodology for constructing a publicationĐlevel classification system of science, Journal of the Association for Information Science and Technology 63(12): 2378-2392.

Yegros, A. and Rafols, I. (2018). Re-assessing priorities in health research. How public R\&D can improve its alignment with health needs, Newsletter of "La Caixa" Foundation. Available at: https://observatoriosociallacaixa.org/en/indicador/-/asset_publisher/ATai9MyKZiYq/content/responde-la-investigacion-a-las-necesidades-de-salud

Zschocke, M. S., Mantin, B. and Jewkes, E. M. (2014). The Effect of Competition on R\&D Portfolio Investments, Production and Operations Management, 23(8): 1439-1449.

\section{AUTHORS}

\section{NICHOLAS S. VONORTAS}

Professor, Institute of International Science and Technology Policy \& Department of Economics, The George Washington University, USA; São Paulo Excellence Chair, University of Campinas, Brazil; Leading Research Fellow, National Research University Higher School of Economics, Russian Federation.

\section{ISMAEL RÀFOLS}

Research Fellow, Ingenio (CSIC-UPV), Universitat Politècnica de València, Spain; Visiting Professor, Centre for Science and Technology Studies (CWTS), University of Leiden, The Netherlands; Associate Researcher, SPRU (Science Policy Research Unit), University of Sussex, UK.
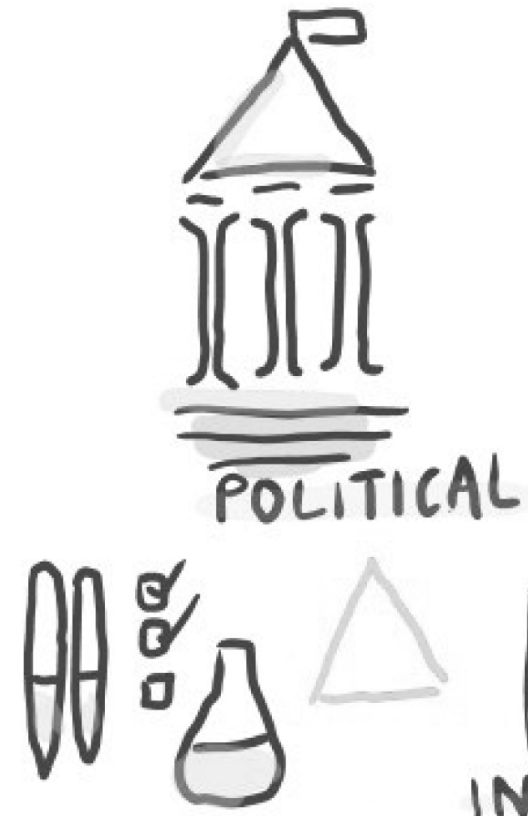